\title{
Nutrient depletions in the Ross Sea and their relation with pigment stocks
}

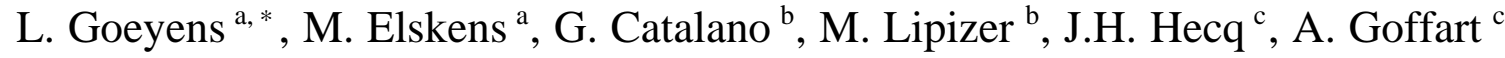 \\ ${ }^{a}$ Vrije Universiteit Brussel, Laboratorium Analytische Chemie, Pleinlaan 2, B-1050 Brussel, Belgium \\ ${ }^{\mathrm{b}}$ Istituto Sperimentale Talassografico, via Gessi 2, 34123 Trieste, Italy \\ ' Université de Liège, Unité d'Ecohydrodynamique B5, B 4000 Liège, Sart-Tilman, Belgium
}

Received 29 March 1999; accepted 3 May 2000

\begin{abstract}
The present article depicts a first attempt to relate the governing nutrient uptake regime and phytopigment signature of the Ross Sea. Based on nutrient and phytopigment data obtained during two cruises in the Ross Sea, two distinct groups were recognised. The first one was characterised by moderate nutrient (nitrate and silicic acid) depletions in combination with relatively high diatom and Phaeocystis abundance. The second group showed very low nutrient depletions and very poor diatom abundance. Average depth specific nitrate depletions were 8.1 and $1.1 \mu \mathrm{M}$ and average silicic acid depletions were 21.5 and $1.3 \mu \mathrm{M}$, respectively. The nutrient consumption patterns did not match the conditions of silicic acid excess (SEA) or nitrate excess areas (NEA), a clear trend being probably obscured by very poor seasonal maturity of several sampling stations.

The contrast between both groups is largely explained by small differences in nitrogen uptake regime of the major phytoplankters. During early season, the diatoms meet the majority of their nitrogen requirements by nitrate uptake, with few exceptions where ammonium is the most important nitrogenous substrate. On average, their nitrate uptake capacity is lower than that of Phaeocystis (average specific nitrate uptake rates were 0.021 and 0.036 day $^{-1}$ for diatoms and Phaeocystis, respectively). The latter phytoplankton always shows predominance of nitrate uptake. Both groups are subject to inhibition of nitrate uptake when ammonium availability increases, and it is likely that the diatoms are more sensitive to the inhibitory effect of ammonium. (C) 2000 Elsevier Science B.V. All rights reserved.
\end{abstract}

Keywords: Ross Sea; nutrient depletions; phytopigments

\section{Introduction}

Earlier investigations on nutrient distributions in the World Ocean stress the occurrence of (1) a decreasing gradient of nitrate excess at silicic acid depletion from the Polar Front towards higher lati-

\footnotetext{
Corresponding author.

E-mail address: leo.goeyens@ihe.be (L. Goeyens).
}

tudes and (2) an area of potential silicic acid excess at nitrate depletion in the Weddell and Ross Seas (Kamykowsky and Zentara, 1985, 1989). Moreover, the Southern Ocean is exceptional within the oceanic realm due to its imposing biogeochemistry, more particularly a plenteous and likely superfluous nutrient supply. The persistence of excess nutrients in the surface layer of the Southern Ocean presumably connotes regulation of nutrient uptake (autotrophic 
processes) by something other than the nutrient availability (Fanning, 1992; Goeyens et al., 1998).

Despite the ubiquitous nutrient abundance in antarctic waters, the intensity of primary production exhibits pronounced spatial variability (cf. a comprehensive comparison by Mathot et al., 1992). Often intensive autotrophic production and concomitantly elevated nutrient removal occur in the immediate vicinity of ice edges (Sullivan et al., 1988). This is not a general rule, however, and sometimes very poor build-up of phytoplankton biomass was observed in the wake of retreating ice (Bathmann et al., 1997; Quéguiner et al., 1997).

Nitrate depletions, defined as the differences between the concentration in the remnant winter water and the in situ concentration (Jennings et al., 1984), are highest in typical marginal ice zone (MIZ) and coastal and continental shelf zone (CCSZ) environments. In contrast, herewith, nitrate removal in the permanently open ocean zone (POOZ) is mostly low, an expression of functional oligotrophy in the ice free antarctic waters (Jones et al., 1990; Tréguer and Jacques, 1992). Intensive vertical mixing within the shelf break area dramatically obscures the temperature minimum, however, and the determination of nutrient depletions is generally not possible during summer.

Furthermore, the nitrate depletions and the corresponding silicic acid depletions are generally disproportionate when compared to their respective availabilities. Even when the general scenario in the Southern Ocean is one of limited nutrient uptake, depletion ratios differ markedly from the ratios of the winter water concentrations, which are available for phytoplankton development at the onset of vernal ice melting. These differences led to the distinction between nitrate excess areas (NEA) and silicic acid excess areas (SEA). The former group exhibits a relatively constant evolution with poor nitrate removal and prevailing absence of dense phytoplankton blooms throughout the season. On average, the nitrate contribution to the total nitrogen requirement of the phytoplankton amounts to $60 \%$. The SEA ecosystems are characterised by elevated nitrate uptake rates during early spring followed by a dramatic decrease in nitrate consumption long before exhaustion of the nitrate pool. Moreover, the contribution of nitrate is highly variable, with maximal values of $\sim 100 \%$ during early spring and lowest contributions of $<25 \%$ during summer (Goeyens et al., 1998). Fertile MIZ and CCSZ waters often demonstrate SEA characteristics.

Satellite imagery revealed that densest phytoplankton blooms in the Ross Sea occur where large offshore polynyas develop during spring (Comiso et al., 1993; Arrigo and McClain, 1994). Moreover, field studies confirm that the Ross Sea exhibits most consistently the largest surface accumulations of phytoplankton biomass in the Southern Ocean (DiTullio and Smith, 1996). In the Ross Sea, pronounced horizontal gradients in phytoplankton distribution are observed, with either diatoms or the colonial prymnesiophyte Phaeocystis antarctica dominating the autotrophic assemblages (Leventer and Dunbar, 1996; Smith et al., 1996; Goffart et al., 2000).

The current paper aims at a better understanding of the nutrient depletion patterns in the Ross Sea during the growth season. Two aspects received our special attention: the distributions and ratios of the dominant phytopigments, which characterise the differences in phytoplankton assemblage (diatom vs. Phaeocystis predominance), and the corresponding nitrogen uptake regime in the different communities.

\section{Methods}

Samples were collected during two Italian Antarctic expeditions: cruise A (sampling between January 01 and 05, 1990) on board RV Cariboo and cruise B (sampling between November 14 and December 15, 1994) on board RV Italica. Cruise A covered the margin area of the continental Ross Shelf east of Cape Adare and a transect through the Ross Sea at a latitude of $\sim 75^{\circ} \mathrm{S}$. During cruise B, sampling was carried out at 27 stations located from $76^{\circ} \mathrm{S}$ to $71^{\circ} \mathrm{S}$ along $175^{\circ} \mathrm{E}$, following the northward ice retreat.

During cruise A, nutrient concentrations were determined by means of a Technicon II Autoanalyzer (Hansen and Grasshoff, 1983), while during cruise B, an Alpkem autoanalyzer was adopted according to "Alpkem Flow Solution Methodologies" (ALPKEM, 1992a,b,c). Ammonium was always determined with a Technicon autoanalyzer, according to the indophenol blue method adapted for segmented flow analyz- 
ers by Tréguer and Le Corre (1975). Hypochlorite solution was used as chlorine donor; freshly prepared Millipore Milli Q water served as the blank solution. Original data on nutrient concentrations are reported by Catalano et al. (1991, 1997).

The nitrate and silicic acid uptake regimes are characterised by the respective nutrient depletions. Le Corre and Minas (1983), Jennings et al. (1984), Goeyens et al. (1995), Rubin et al. (1998) and Hoppema et al. (2000) have previously used depletion calculations in antarctic research. Calculated nutrient depletions represent seasonally integrated nutrient removal in the surface layer down to the depth, where the in situ nitrate and silicic acid concentrations equal the winter values $\mathrm{NiWi}$ and $\mathrm{SiWi}$, respectively. Nitrate depletion (NiDe) values are believed to be associated with "new" production, sensu Dugdale and Goering (1967). The silicic acid depletion ( $\mathrm{SiDe}$ ), on the other hand, depicts diatom production. Hence, diatom abundance and productivity are very relevant parameters shaping the nutrient distributions and more particularly the nutrient depletion ratios in the surface layer.

As pointed out by the above cited authors, there are some implicit assumptions in using this methodology. Nutrient depletion values can be biased by either physical reintroduction or biological processes such as nitrification (Bianchi et al., 1997), and should therefore be considered as minimal values. Moreover, it must be stressed that NiDe does not reflect total dissolved nitrogen uptake since concomitant uptake of other nitrogenous nutrients such as dinitrogen, ammonium and dissolved organic nitrogen is not negligible (Bronk et al., 1994). Most important is the assumption that vertical and lateral mixing in both the temperature minimum and surface layer are small. This condition is fulfilled; the evidence herefor is that the observed temperature in the remnant winter water is approximately equal to the temperature in the winter surface water (near the freezing point: all values are $\leq-1.70^{\circ} \mathrm{C}$ ). Additionally, fluxes due to vertical gradients in the surface layer should be small. Taking into consideration a coefficient of diffusion of $8 \mathrm{~m}^{2}$ day $^{-1}$ (Gordon et al., 1984), the maximal contributions from vertical fluxes could amount to $1 \%$ and $13 \%$ for nitrate and silicic acid depletions, respectively. These values are in good agreement with earlier determined deviations
(Goeyens et al., 1991, 1995). Finally, possible nutrient changes due to the addition of melt water from the sea ice should be accounted for by normalization to a constant salinity; a detailed procedure for calculating the depletions is given by Hoppema et al. (2000). In the current investigation, no corrections for possible dilution by melting ice were introduced, since there is no evidence for enhanced effects when considering average nutrient concentrations and salinities of sea ice and a "conservative" nutrient to salinity relation in the surface water (Goeyens et al., 1995). This study is largely founded on comparisons with earlier studies; hence, the authors are confident that the general pattern is well described by the data given and that the closeness of agreement between the given and correct values (or the accuracy of the data) is comprised within the maximal deviation of $15 \%$.

Pigment concentrations were obtained with HPLC techniques; pigment stocks represent the integrated concentrations of chlorophyll $a(\mathrm{Chl} a)$, fucoxanthin (Fuco) and 19'-hexanoyl-oxyfucoxanthin (HF), respectively down to the temperature minimum layer. The integration is also based on six to eight samplings at discrete depths in the water column, confined between surface and temperature minimum layers. Particulate matter for pigment analysis was separated by low vacuum filtration of 11 of sea water onto Whatman GF/F filters. Afterwards, the filters were immediately frozen at $-25^{\circ} \mathrm{C}$ until analysis on board. Frozen filters were extracted in $100 \%$ methanol, using grinding and refiltration to remove cellular debris. Phytoplankton pigments were separated and quantified by HPLC, following the procedure of Williams and Claustre (1991). Chl $a$ is used as the universal index of phytoplankton biomass. Fuco and HF are used as chemotaxonomic tools to identify diatoms (Jeffrey, 1980; Claustre et al., 1994) and prymnesiophytes (Gieskes and Kraay, 1986; DiTullio and Smith, 1995), respectively. The HF stock is assumed to be indicative of the presence of Phaeocystis. This assumption is based on the reported predominance of Phaeocystis and minor contribution of other prymnesiophytes in the Ross Sea (Palmisano et al., 1986; DiTullio and Smith, 1995; Goffart et al., 2000).

Samples for productivity incubations were obtained from depths corresponding to $100 \%, 50 \%$, 
$20 \%, 10 \%, 5 \%, 1 \%$ and exceptionally $0.1 \%$ of PAR with a CTD rosette fitted with 24 Niskin bottles of 12 1. Nitrogen uptake rates were determined with tracer experiments according to Dugdale and Goering (1967), using the stable isotope ${ }^{15} \mathrm{~N}$ and following the JGOFS protocols and the analytical procedures described by Owens (1988) and Owens and Rees (1989). From each depth, two subsamples were transferred into 11 polycarbonate bottles covered with perforated nickel screens to mimic the in situ irradiance conditions. The samples were spiked respectively with $\mathrm{Na}^{15} \mathrm{NO}_{3}\left(99.9 \%{ }^{15} \mathrm{~N}\right)$ and ${ }^{15} \mathrm{NH}_{4} \mathrm{Cl}$ $\left(70.4 \%{ }^{15} \mathrm{~N}\right)$, placed in on-deck incubators and maintained at sea-surface temperature with running seawater. After $24 \mathrm{~h}$ of incubation, the samples were filtered on precombusted Whatman GF/F filters (25 $\mathrm{mm}$ diameter), rinsed with filtered seawater and stored frozen until isotope analysis with a continuous flow nitrogen analyzer-mass spectrometer (ANCA 20-20 MS, Europa Scientific). Original data on nitrogen uptake are reported in Lipizer and Catalano (1999). Specific uptake rates $\left(\nu\right.$, in day $\left.{ }^{-1}\right)$ are defined as the nutrient removed per unit of particulate nitrogen (PN) and per unit of time; absolute uptake rates or transport rates $\left(\rho\right.$, in $\mathrm{nM}$ day $\left.^{-1}\right)$ are the products of specific uptake rates and PN concentrations (Wilkerson and Dugdale, 1992). The relative importance of new vs. total production was expressed as the $f$-ratio (Eppley and Peterson, 1979).

\section{Results and discussion}

A compilation of all $\mathrm{NiDe}$ and $\mathrm{SiDe}$ values of both cruises $\mathrm{A}$ and $\mathrm{B}$ emphasizes predominantly poor nutrient consumption with few enhanced values only (Table 1). Both the average and median nutrient depletions are very low, their corresponding interquartile ranges vary from 7 to $70 \mathrm{mmol} \mathrm{m}^{-2}$ and from 5 to $72 \mathrm{mmol} \mathrm{m}^{-2}$ for $\mathrm{NiDe}$ and $\mathrm{SiDe}$, respectively. Only a small number of higher values - all referring to cruise $\mathrm{A}$ - corresponds to the ones typically observed in productive antarctic waters (Jennings et al., 1984; Karl et al., 1991; Goeyens et al., 1995). Additionally, ammonium concentrations as well as pigment stocks are low. Ammonium stocks never exceed $50 \mathrm{mmol} \mathrm{m} \mathrm{m}^{-2}$, with corresponding ambient concentrations of $<0.5 \mu \mathrm{M}$ throughout. Chl $a$ concentrations $\geq 1 \mu \mathrm{g} \mathrm{1^{-1 }}$, worthy of the term phytoplankton bloom (Sakshaug and HolmHansen, 1984), were rarely observed. These parameters corroborate prevalence of early season conditions during the sampling periods.

However, the NiDe and SiDe patterns do not match the pronounced distinction between NEA and SEA conditions. Generally, the specific depletion ratios (defined as the quotients of the depletion to winter concentration ratios) largely exceed 1 in NEA surface waters, whereas the opposite holds for the SEA. Our observations in the Ross Sea fit an intermediate situation with all ratios amounting to approximately 1 (the $95 \%$ confidence interval ranges from 0.87 to 1.12 , Fig. 1A). Few stations adhere conceptually to the NEA conditions with ratios slightly $>1$, whereas most of the stations adhere to the SEA conditions with ratios slightly $<1$. On average, NEA and SEA specific depletion ratios from the current investigation amount to 1.24 and to 0.76 (Fig. 1B,C). These values are significantly different from the earlier determined specific depletion ratios of 2.68 (NEA) and 0.40 (SEA), respectively. The latter values are derived from a comparative

Table 1

Nutrient and pigment status of the Ross Sea during cruises A and B

\begin{tabular}{lcccrrr}
\hline & $\begin{array}{l}\text { NiDe } \\
\left(\mathrm{mmol} \mathrm{m}^{-2}\right)\end{array}$ & $\begin{array}{l}\text { SiDe } \\
\left.(\mathrm{mmol} \mathrm{m})^{-2}\right)\end{array}$ & $\begin{array}{l}\text { Ammonium } \\
\left(\mathrm{mmol} \mathrm{m}^{-2}\right)\end{array}$ & $\begin{array}{l}\text { Chl } a \\
\left(\mu \mathrm{g} \mathrm{m}^{-2}\right)\end{array}$ & $\begin{array}{l}\text { Fuco } \\
\left(\mu \mathrm{g} \mathrm{m}^{-2}\right)\end{array}$ & $\begin{array}{l}\mathrm{HF} \\
\left(\mu \mathrm{g} \mathrm{m}^{-2}\right)\end{array}$ \\
\hline Average & 61 & 127 & 7.5 & 42448 & 19261 & 20351 \\
Median & 16 & 13 & 4.9 & 28446 & 5868 & 6603 \\
Minimum & 1 & 0 & 0.1 & 3480 & 695 & 179016 \\
Maximum & 48 & 1362 & 49.2 & 159553 & 2483 & 3574 \\
First quartile & 7 & 5 & 2.6 & 61648 & 15420 & 31916 \\
Third quartile & 70 & 72 & 10.5 & & & \\
\hline
\end{tabular}



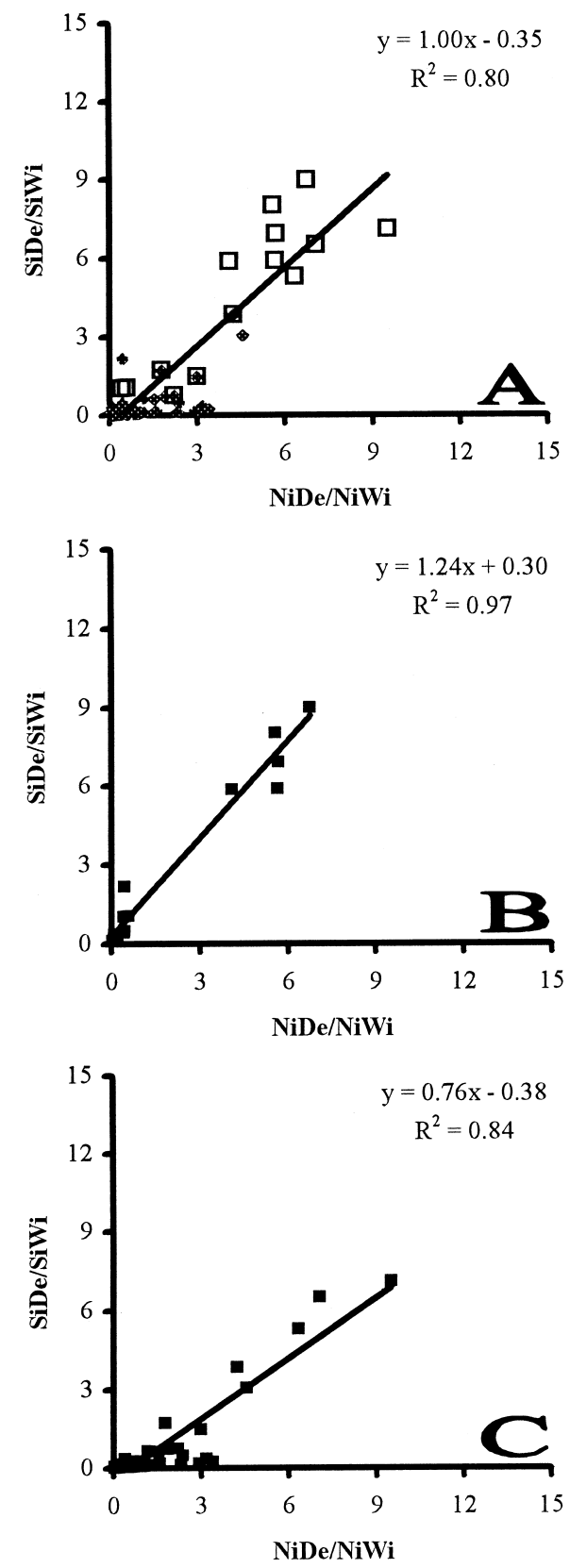

Fig. 1. Specific silicic acid depletion vs. specific nitrate depletion for all available data (A), for the stations adhering to NEA conditions (B) and for the stations adhering to the SEA conditions (C); open squares represent cruise A data (enhanced seasonal maturity) and black diamonds represent cruise B data (poor seasonal maturity), specific nutrient depletions are defined as the ratios of the depletion over the winter concentration. study based on nutrient uptake data obtained during five different cruises in the Atlantic and Indian sectors of the Southern Ocean (Goeyens et al., 1998). Presumably, "the very early season" conditions observed during cruise B (1994, RV Italica) obscure the distinction between NEA and SEA conditions. The observed maximal depletions are a factor of 2 or more less than the maximal values observed in areas of intensive nutrient removal such as the MIZ and CCSZ of the Weddell Sea and Prydz Bay (Goeyens et al., 1998).

Any departure of the SiDe/NiDe ratio from the $\mathrm{SiWi} / \mathrm{NiWi}$ ratio, meaning that the nutrient removal ratio differs from the nutrient availability ratio, signifies that NiDe and SiDe are disproportionate due to differences in either the Si uptake regime (predominant vs. reduced abundance of diatoms) or the $\mathrm{N}$ uptake regime (oxidised vs. reduced nitrogen assimilation). Our data set of all depth specific depletions (the differences between the concentration in the temperature minimum layer and the in situ concentration at a particular sampling depth) emphasizes that the $\mathrm{SiDe} / \mathrm{NiDe}$ ratios fall apart in two distinct groups (Fig. 2). The first one (group 1) shows largely variable $\mathrm{SiDe}$ values and constantly low $\mathrm{SiDe} / \mathrm{NiDe}$

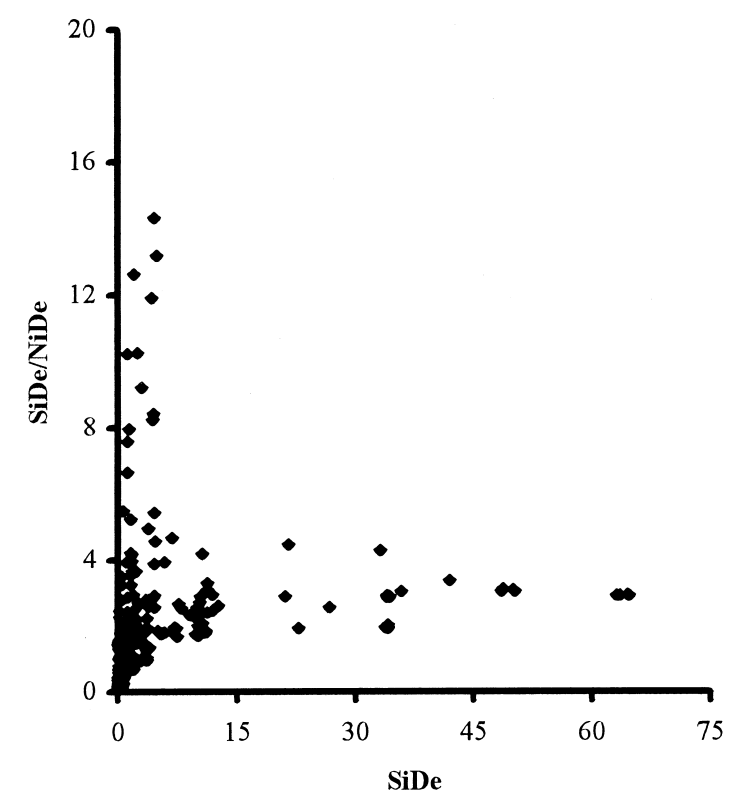

Fig. 2. Depletion ratios vs. silicic acid depletions for all available data. 
ratios, indicating a variation of both the $\mathrm{SiDe}$ and NiDe values in concert with each other. The second one (group 2), on the contrary, gathers stations with consistently low SiDe values and highly variable $\mathrm{SiDe} / \mathrm{NiDe}$ ratios.

The contrast between both groups is addressed by the comparison of the nutrient uptake regimes and corresponding pigment contents. Differences are summarised in Table 2. Basically, the NiDe, SiDe, Chl $a$ and Fuco stocks of group 1 (constantly low $\mathrm{SiDe} / \mathrm{NiDe}$ ratios) are significantly higher than those of group 2 (consistently low SiDe values). The HF stocks display a completely different pattern, however, with similarly high values and a well comparable spread in both groups. Maximal HF stocks even occur in group 2. A hasty look at the data learns that denser phytoplankton with relatively high diatom abundances are responsible for considerable nitrate and silicic acid uptake in group 1. On the other hand, group 2 is characterised by dilute phytoplankton assemblages with poor diatom and considerable Phaeocystis abundances, which induced rather low silicic acid removal. The occurrence of Phaeocystis dominated populations in the Southern Ocean, more particularly in the Ross Sea, has not gone unnoted (El-Sayed et al., 1983; Palmisano et al., 1986; Smith and Sakshaug, 1990; Davidson and Marchant, 1992; Smith et al., 1996; Arrigo et al., 1998; Lancelot et al., 1998) and their presence and conceivable dominance in the phytoplankton community are likely to affect the nutrient uptake.

Antarctic phytoplankton can either exhibit pronounced seasonal variability in community structure or not. Generally, diatom to non-diatom succession constitutes the most important shift, with bottom-up control as well as top-down control being the steering parameters (Semeneh et al., 1998a,b). This study reveals remarkable differences in Phaeocystis and diatom dominance during the earliest stage of the growth season in the Ross Sea, whereby the governing physical conditions are largely determining the phytoplankton distribution (Goffart et al., 2000). The corresponding nitrogen utilisation evidences some small differences between Phaeocystis and diatom predominance, the overall trend being highly characteristic for the onset of the phytoplankton development after ice melting though (Cota et al., 1992; Goeyens et al., 1995). A summary of the major nitrogen uptake characteristics measured during cruise B only is given in Table 3 .

The absolute nitrate uptake rates range from $\sim 1$ to $\sim 300 \mathrm{nM}$ day $^{-1}$ and the corresponding specific uptake rates range from $\sim 0.001$ to $\sim 0.12$ day $^{-1}$. The maximal rates are in good agreement with values from earlier investigations during the onset of the productive season (shortly after melting of the

Table 2

Variations in nutrient depletion and pigment stock of groups 1 and 2

\begin{tabular}{|c|c|c|c|c|c|}
\hline & $\begin{array}{l}\text { NiDe } \\
(\mu \mathrm{M})\end{array}$ & $\begin{array}{l}\mathrm{SiDe} \\
(\mu \mathrm{M})\end{array}$ & $\begin{array}{l}\text { Chl } a \\
\left(\mathrm{ng} \mathrm{l}^{-1}\right)\end{array}$ & $\begin{array}{l}\text { Fuco } \\
\left(\text { ng }^{-1}\right)\end{array}$ & $\begin{array}{l}\mathrm{HF} \\
\left(\mathrm{ng} \mathrm{1^{-1 }}\right)\end{array}$ \\
\hline \multicolumn{6}{|l|}{ Group 1} \\
\hline Average & 8.1 & 21.5 & 2219 & 1840 & 427 \\
\hline Median & 4.9 & 11.3 & 1877 & 1200 & 264 \\
\hline Minimum & 0.4 & 5.0 & 235 & 37 & 44 \\
\hline Maximum & 22.1 & 64.7 & 6756 & 6801 & 2377 \\
\hline First quartile & 3.7 & 10.1 & 895 & 491 & 142 \\
\hline Third quartile & 11.9 & 34.2 & 3030 & 3255 & 495 \\
\hline \multicolumn{6}{|l|}{ Group 2} \\
\hline Average & 1.1 & 1.3 & 1093 & 273 & 679 \\
\hline Median & 0.9 & 0.7 & 508 & 136 & 233 \\
\hline Minimum & 0.1 & 0.1 & 146 & 30 & 26 \\
\hline Maximum & 4.5 & 4.8 & 4070 & 1953 & 3065 \\
\hline First quartile & 0.4 & 0.3 & 329 & 65 & 91 \\
\hline Third quartile & 1.6 & 1.9 & 1853 & 296 & 1294 \\
\hline
\end{tabular}


Table 3

Summary of the depth averaged values characterising the nitrogen uptake regime during cruise B in the Ross Sea

\begin{tabular}{|c|c|c|c|c|}
\hline & Average & Median & Minimum & Maximum \\
\hline Absolute nitrate uptake rate (nM day $\left.{ }^{-1}\right)$ & 33.84 & 5.33 & 1.04 & 308.08 \\
\hline Specific nitrate uptake rate $\left(\right.$ day $\left.^{-1}\right)$ & 0.0243 & 0.0103 & 0.0015 & 0.1169 \\
\hline Absolute ammonium uptake rate $\left(\mathrm{nM}\right.$ day $\left.^{-1}\right)$ & 12.27 & 4.03 & 0.42 & 112.39 \\
\hline Specific ammonium uptake rate $\left(\right.$ day $\left.^{-1}\right)$ & 0.0137 & 0.0076 & 0.0008 & 0.0501 \\
\hline$f$-Ratio & 0.64 & 0.60 & 0.25 & 0.93 \\
\hline Ammonium/nitrate uptake ratio & 0.68 & 0.66 & 0.08 & 2.98 \\
\hline
\end{tabular}

winter ice) in the Ross Sea (Nelson and Smith, 1986) and in other regions of the Southern Ocean (Olson, 1980; Nelson et al., 1987; Karl et al., 1991; Kristiansen et al., 1992; Bury et al., 1995). They corroborate typical SEA conditions as proposed by Kamykowsky and Zentara $(1985,1989)$ and Goeyens et al. (1998). Minute differences with the highest maximal rates observed by other authors in well sheltered and very fertile regions must be explained by limited seasonal maturity and inherently low biomass build-up at the sampling moment.

Additionally, ammonium uptake exhibits less pronounced differences between minimal and maximal uptake rates, a common feature of the nitrogen uptake regime in the World Ocean. The maximal specific uptake rates $\left(\sim 0.05\right.$ day $^{-1}$ or $\left.\sim 0.002 \mathrm{~h}^{-1}\right)$ compare well to the ones observed during previous early spring studies (Olson, 1980; Nelson et al., 1987; Karl et al., 1991; Kristiansen et al., 1992; Bury et al., 1995).

In order to distinguish the nitrogen uptake by Phaeocystis dominated and by diatom dominated assemblages, we arbitrarily defined that 10 stations with minimal Fuco/HF ratios were Phaeocystis dominated stations (PDS) and, otherwise, that 10 stations with highest Fuco/HF ratios were diatom dominated stations (DDS). It must be stressed here that PDS and DDS do not refer to the above-mentioned groups 1 and 2; moreover, these data were collected during cruise B only. The investigated pigment stocks and corresponding nitrogen uptake rates are depth-integrated values for the euphotic layer down to the minimal PAR value. They are snapshots of the ambient conditions at the sampling moment but do not include a seasonal dimension such as the nutrient depletions compared in Table 2. The variability in nitrogen uptake dynamics is summarised in Tables 4 and 5, respectively. The PDS are charaterised by increasing nitrate uptake rates, which occur in concert with increasing ammonium uptake rates (Fig. 3A). The maximal observed values amount to $>300 \mathrm{nM} \mathrm{day}^{-1}$ and to $>100 \mathrm{nM}$ day $^{-1}$ for nitrate and ammonium, respectively, with the highest values meeting HF stocks and overall phytoplankton biomasses ( $\mathrm{Chl} a$ ) above the average. However, two stations with highest $\mathrm{HF}$ and $\mathrm{Chl} a$ concentrations exhibit intermediate uptake rates. Estimating their seasonal maturity by taking the ratio of the respective NiDe and $\rho-\mathrm{NO}_{3}$ values (Goeyens et al., 1998), it cannot be excluded that phytoplankton ingested nitrate at higher uptake rates before being sampled and that seasonal progress proceeded already for a longer time span in those particular water columns. DDS display a less obvious relation of the nitrate vs.

Table 4

Summarised nitrogen uptake regime in the Phaeocystis dominated samples

\begin{tabular}{|c|c|c|c|c|}
\hline & Average & Median & Minimum & Maximum \\
\hline Absolute nitrate uptake rate $\left(\mathrm{nM}\right.$ day $\left.^{-1}\right)$ & 87.27 & 44.37 & 1.04 & 308.08 \\
\hline Specific nitrate uptake rate $\left(\right.$ day $\left.^{-1}\right)$ & 0.0362 & 0.0176 & 0.0033 & 0.1044 \\
\hline Absolute ammonium uptake rate $\left(\mathrm{nM}\right.$ day $\left.^{-1}\right)$ & 23.15 & 6.18 & 0.42 & 112.39 \\
\hline Specific ammonium uptake rate $\left(\right.$ day $\left.^{-1}\right)$ & 0.0092 & 0.0059 & 0.0010 & 0.0293 \\
\hline$f$-Ratio & 0.73 & 0.69 & 0.56 & 0.93 \\
\hline Ammonium/nitrate uptake ratio & 0.42 & 0.45 & 0.08 & 0.77 \\
\hline
\end{tabular}


Table 5

Summarised nitrogen uptake regime in the diatom dominated samples

\begin{tabular}{lllll}
\hline & Average & Median & Minimum & Maximum \\
\hline Absolute nitrate uptake rate $\left(\mathrm{nM} \mathrm{day}^{-1}\right)$ & 10.84 & 9.04 & 2.04 & 34.14 \\
Specific nitrate uptake rate $\left(\right.$ day $\left.^{-1}\right)$ & 0.0211 & 0.0079 & 0.0015 & 0.1169 \\
Absolute ammonium uptake rate $\left(\mathrm{nM} \mathrm{day}^{-1}\right)$ & 8.50 & 6.46 & 1.07 & 36.10 \\
Specific ammonium uptake rate $\left(\right.$ day $\left.^{-1}\right)$ & 0.0179 & 0.0153 & 0.0010 & 0.0383 \\
$f$-Ratio & 0.52 & 0.51 & 0.23 & 0.81 \\
Ammonium/nitrate uptake ratio & 0.86 & 0.69 & 0.12 & 2.98 \\
\hline
\end{tabular}

ammonium uptake; more particularly the maximal uptake rates are nearly one order of magnitude lower than the ones observed for PDS (Table 5, Fig. 3B). Since absolute uptake rates combine specific uptake rates and concentrations of particulate matter, the differences in uptake dynamics emphasize the role of
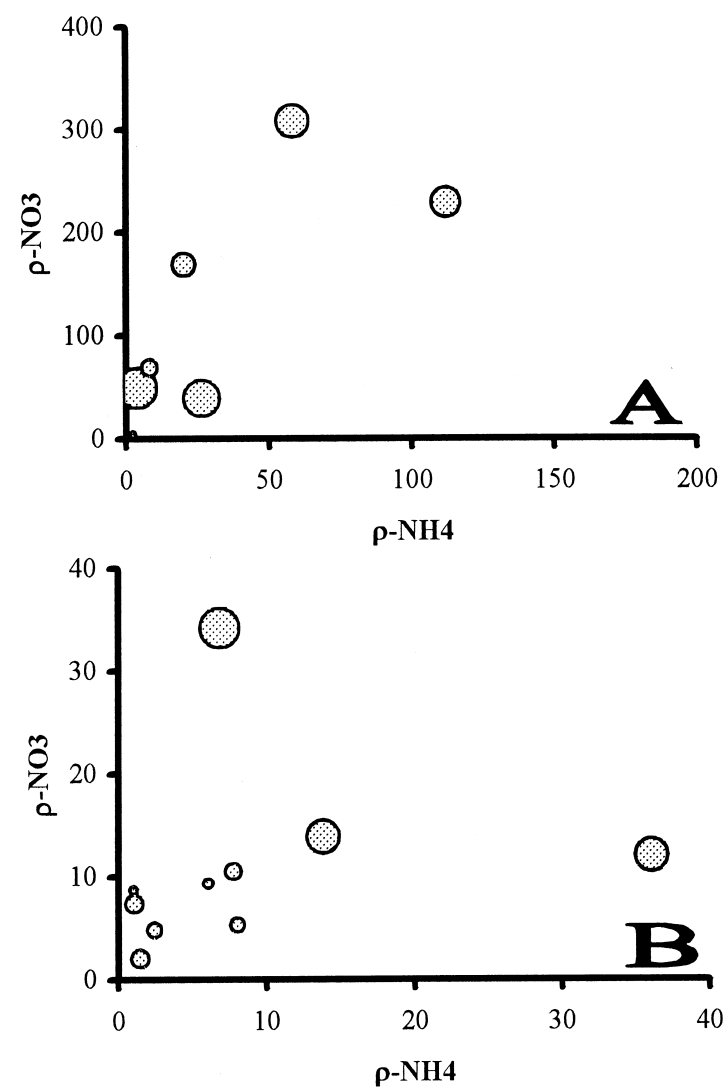

Fig. 3. Variation of the absolute nitrate and absolute ammonium uptake rates (nM day $\left.{ }^{-1}\right)$ in Phaeocystis dominated samples (A) and diatom dominated samples (B); bubble sizes correspond to relative phytoplankton biomasses in the samples. both the biomasses and uptake capacities (or specific uptake rates). Fig. 4A and B in fact reveals important differences in specific uptake rates (absolute uptake rates normalized to the corresponding biomasses). Particularly in the PDS, the trend is one of enhanced nitrate uptake capacity and reduced ammonium uptake capacity. The interquartiles for nitrate uptake (50\% of the data) range from $\sim 0.01$ to $\sim 0.06$ day $^{-1}$ and from $\sim 0.01$ to $\sim 0.02$ day $^{-1}$ in the PDS and DDS, respectively, meaning that a majority of the Phaeocystis has three times higher nitrate uptake capacity. Seemingly, Phaeocystis manifest themselves as the better nitrate removers. On the other hand, the diatoms demonstrate a little lead over Phaeocystis, with the ammonium uptake rate's interquartile range being twice the one of the nitrate uptake. This general pattern as it is observed for depth weighted averages of the nitrogen uptake rates is in perfect agreement with the uptake regime in the Chl a maximum layer of each station (data not shown).

It is commonly accepted that increased ammonium availability inhibits nitrate uptake (Dortch, 1990), and that this regulatory effect of ammonium contributes to the considerable reduction of the nitrate uptake rate long before the nitrate pool of antarctic surface waters is exhausted (Goeyens et al., 1995). This contention is confirmed by the current data set. With the exception of 1 single data point, all nitrate transport rate values remain very low when the ammonium stocks exceed $5 \mathrm{mmol} \mathrm{m} \mathrm{m}^{-2}$ (Fig. 5A). The only elevated uptake rate $\left(\rho-\mathrm{NO}_{3}=\right.$ $228.6 \mathrm{nM} \mathrm{day}^{-1}$ ) must be explained by a comparingly denser phytoplankton biomass since the plot with specific nitrate uptake rates vs. ammonium stocks does not reveal any significant "deviation" (Fig. 5B). Our small data set indicates that the 

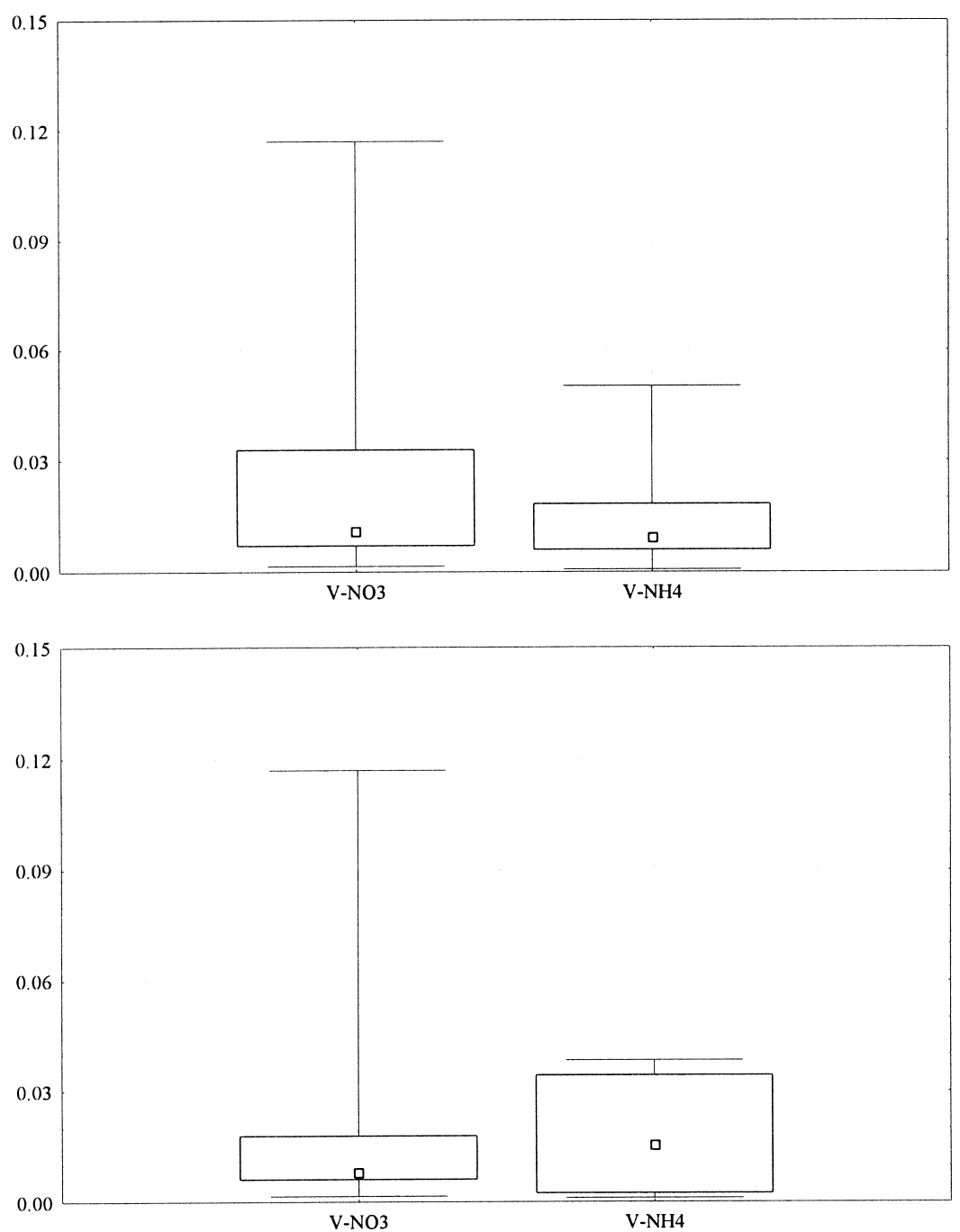

Fig. 4. Box and whisker plots for the non-parametric distributions of specific nitrate and ammonium uptake rates (day ${ }^{-1}$ ) in Phaeocystis dominated samples (A) and in diatom dominated samples (B).

diatom-dominated populations show generally a lower nitrate uptake capacity. There is only 1 higher value of $\sim 0.10 \mathrm{day}^{-1}$ corresponding to a negligible ammonium stock; otherwise the uptake rates remain very low $\left(<0.03 \mathrm{day}^{-1}\right.$, Fig. 4$)$. This contrasts with the values obtained for PDS were the average specific nitrate uptake rate at low ammonium is generally higher. It must be stressed here that all stations are characterised by a very low ammonium load, however. The maximal stocks never exceed $30 \mathrm{mmol}$ $\mathrm{m}^{-2}$, meaning that the ambient concentrations in the water column are generally $<0.3 \mu \mathrm{M}$. These concentrations are significantly lower then the "elevated" values generally observed in the vicinity of land and in ice edge zones, which can exceptionally exceed 4 $\mathrm{M}$ (Koike et al., 1986; Owens et al., 1991).

On the other hand, a compensatory increase of the ammonium uptake at higher ammonium availability does generally not occur. This study confirms that increased ammonium transport rates at higher ammonium availabilities (percentages of ammonium- $\mathrm{N}$ in the total inorganic nitrogen pool) do not equal the 

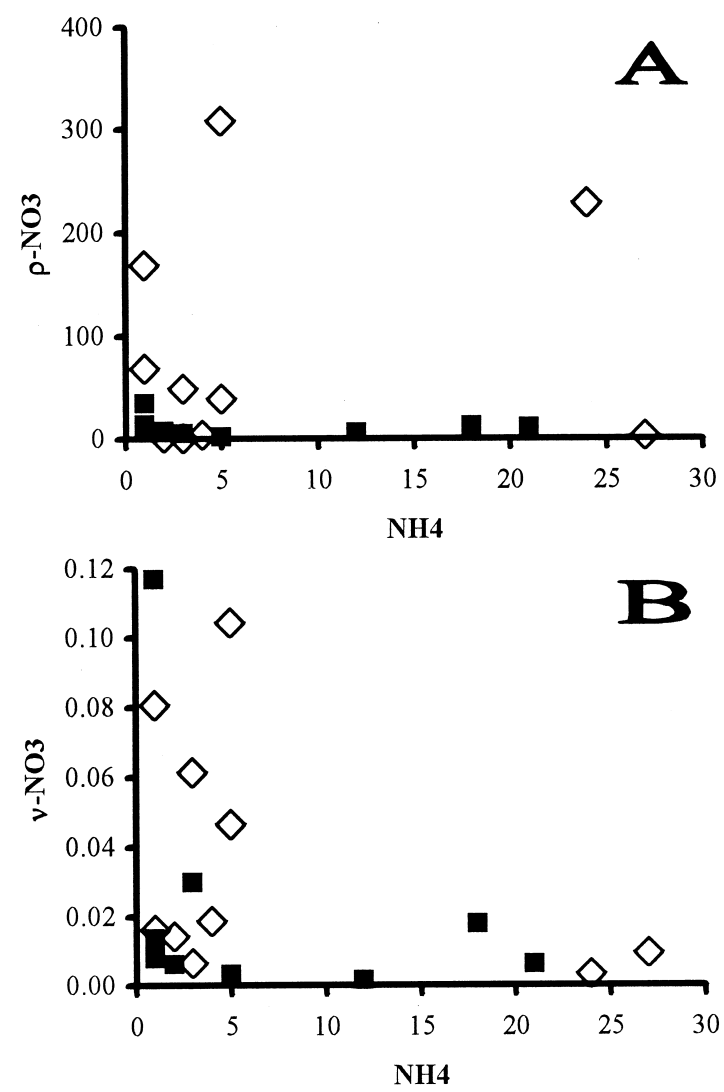

Fig. 5. Illustration of the inhibitory effect of increasing ammonium concentrations $\left(\mathrm{mmol} \mathrm{m} \mathrm{m}^{-2}\right)$ on the absolute nitrate uptake rate (A) and specific nitrate uptake rate (B); open diamonds represent Phaeocystis dominated samples and black squares represent diatom dominated samples.

differences between maximal and minimal nitrate uptake rates (Fig. 6). The highest observed ammonium uptake rate value, which amounts to $>100 \mathrm{nM}$ day $^{-1}$, corresponds with an ammonium availability of $1.7 \%\left(>20 \mathrm{mmol} \mathrm{m}^{-2}\right.$ ) and with a maximal Phaeocystis predominance (Fig. 6A). The average trend in PDS is one of increasing uptake rate for increasing availability and increasing Phaeocystis abundance. The DDS display 1 significantly increased ammonium uptake rate at an ammonium availability of $2.2 \%$ in addition to consistently low uptake rates throughout (Fig. 6B). The maximal uptake rate does not exceed $40 \mathrm{nM}$ day $^{-1}$, however, a value that remains a factor of 3 below the maximal PDS uptake rate. These higher ammonium uptake rates in the PDS must be explained by higher biomasses, since no significant differences in specific uptake rate can underpin a distinction in uptake capacity between PDS and DDS (Fig. 4A and B). On the contrary, even when the ammonium uptake capacity remains low, the diatom-dominated populations are slightly better ammonium utilisers as already shown by Fig. 4B.
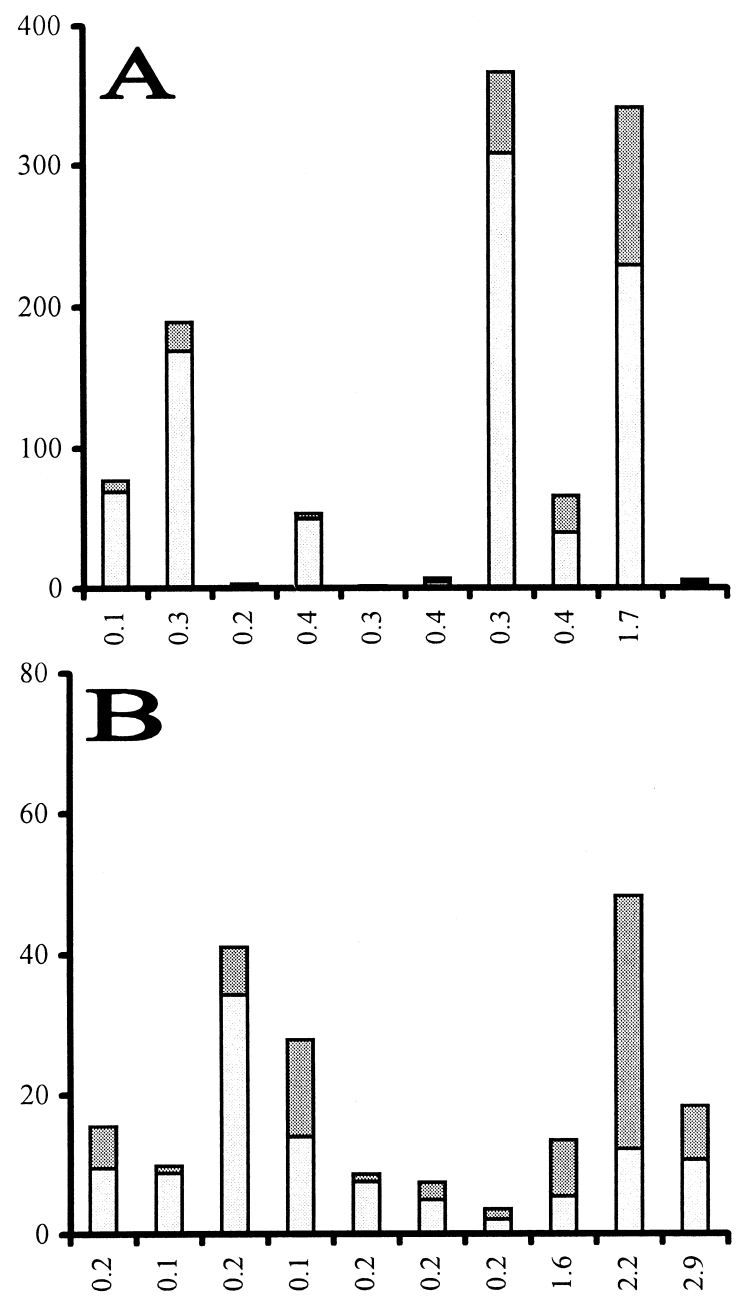

Fig. 6. Variability of nitrate and ammonium contributions to the total absolute uptake rate (nM day ${ }^{-1}$ ) as a function of ammonium availabilities (\%) in Phaeocystis dominated samples (A) and in diatom dominated samples (B); ammonium availabilities are percentages of ammonium- $\mathrm{N}$ in the dissolved inorganic nitrogen pool, clear columns represent nitrate uptake and dark columns represent ammonium uptake. 


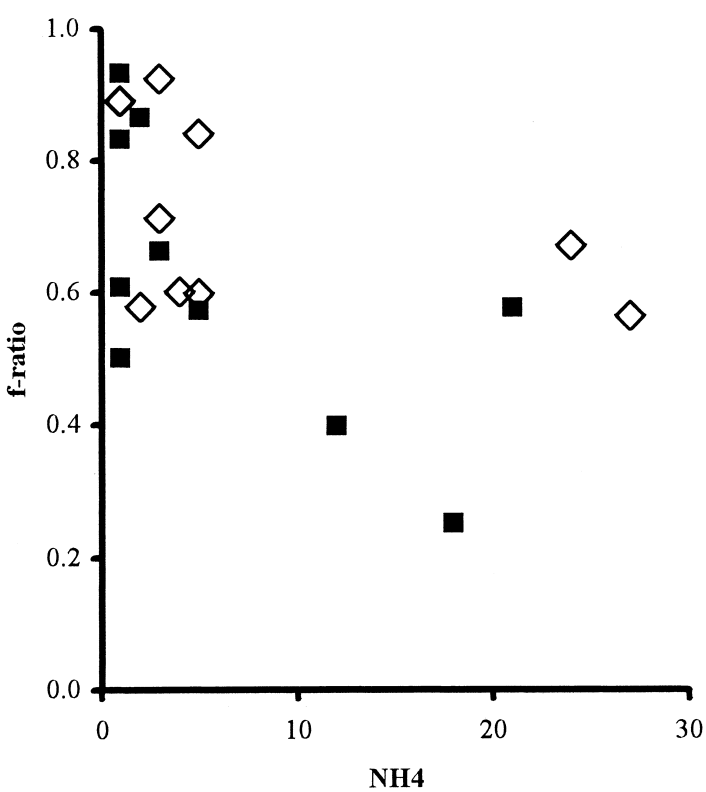

Fig. 7. Variability of $f$-ratios as a function of ammonium stocks (mmol $\mathrm{m}^{-2}$ ); open diamonds represent Phaeocystis dominated samples and black squares represent diatom dominated samples.

Variations in nitrate and ammonium utilisation determine the differences in nitrogen uptake regime of PDS and DDS. The $f$-ratio, which reflects the contribution of nitrate uptake in the total dissolved nitrogen uptake, is known to decrease when ammonium becomes more available. Fig. 7 shows that the nitrogen uptake regime of PDS is generally characterised by the larger nitrate contribution, with all $f$-ratios exceeding 0.5 ; the $f$-ratios in DDS, on the contrary, drop to values $<0.5$ when ammonium is moderately available. This is in no way exceptional: diatom dominated populations evolving to regenerated production were observed during other studies in the Southern Ocean (Semeneh et al., 1998a,b).

\section{Conclusions}

Many of the considered data refer to the early season conditions of the study area. The average nitrate and silicic acid depletions amount to 61 and $127 \mathrm{mmol} \mathrm{m}^{-2}$ respectively, low values when compared to the maximal depletions observed in productive antarctic waters. Moreover, it was observed that no pronounced ammonium accumulation in the water occurred at the sampling time, what confirms the poor seasonal maturity of the studied region.

The authors conclude that phytopigment data in addition to information on the nutrient uptake regime sheds some new light on the vernal evolution in the Ross Sea polynya. Phytoplankton development can either result in Phaeocystis dominated or diatom dominated phytoplankton. Nitrate is throughout the major nitrogenous nutrient and the small number of data suggests that Phaeocystis are the better competitors in terms of uptake capacity: on average Phaeocystis dominated assemblages exhibit higher specific nitrate uptake rates than diatom dominated ones.

The occurrence of significant decreases in nitrate uptake at enhanced ammonium availability suggests that both Phaeocystis and diatom dominated populations suffer from the inhibitory effect of ammonium even at relatively low ambient concentrations. Whether diatoms or Phaeocystis are the more sensitive phytoplanktons is hard to determine with the present data. Nevertheless, the diatoms show a consistently lower nitrate uptake capacity and other studies stress that inhibition by ammonium strikes mainly this community ( $\mathrm{S}$. Tungaraza, personal communication). On the other hand, there is no evidence for compensation of the reduced nitrate uptake by a parallel increase in ammonium uptake.

Part of the sampled stations is characterised by simultaneously developing diatoms and Phaeocystis (group 1). They show considerable nitrate and silicic acid depletions and proportionate removal of both nutrients, a rather plausible nutrient signature when considering that both species assimilate predominantly nitrate and that ammonium contributes little to the total nitrogen uptake during spring. Other stations display extremely poor diatom biomass and prevalence of Phaeocystis (group 2). The latter phytoplankton satisfied their nitrogen requirements for the largest part by nitrate, but due to the extreme shortness of the productive season (and ice-free conditions of the sea) depletions remained low throughout. Very low SiDe (corresponding to poor diatom abundance) in combination with disproportionately high NiDe (corresponding to enhanced Phaeocystis abundance) automatically leads to the lowest $\mathrm{SiDe} / \mathrm{NiDe}$ ratios. On the contrary, poor biomass of 
both diatoms and Phaeocystis as well as reduced vertical stability and disproportionate nutrient replenishment due to the uncoupling of nitrate and silicic acid regeneration might have caused the highest $\mathrm{SiDe} / \mathrm{NiDe}$ ratios.

Prominent evidence for potential excess of either nitrate or silicic acid is absent; this must be explained by the very low seasonal maturity, the inherently small ammonium build-up and the low ammonium uptake rates. Therefore, an obvious distinction between NEA and SEA environments is not possible and, hence, the obtained results do not allow a straightforward confirmation of Kamykowsky and Zentara $(1985,1989)$ original contention.

\section{Acknowledgements}

We take the opportunity to thank the captains and crew members of the research vessels. The present study was funded by the Belgian Research Programme on the Antarctic (phases III and IV) and by the Italian National Programme of Antarctic Researches (PNRA). Jean Henri Hecq is a research associate at the Fonds National de la Recherche Scientifique (FNRS, Belgium).

\section{References}

ALPKEM, 1992a. Nitrate plus nitrite in seawater. The Flow Solution Methodology Doc. No. 000630, 8/92 Rev. B, 19.

ALPKEM, 1992b. Orthophosphate in seawater. The Flow Solution Methodology Doc. No. 000626, 4/92 Rev. A, 16.

ALPKEM, 1992c. Silica in seawater. The Flow Solution Methodology Doc. No. 000671, 5/92 Rev. A, 16.

Arrigo, K.R., McClain, C.R., 1994. Spring phytoplankton production in the Western Ross Sea. Science 266, 261-263.

Arrigo, K.R., Robinson, D.H., Worthen, D.L., Schieber, B., Lizotte, M.P., 1998. Bio-optical properties of the southwestern Ross Sea. J. Geophys. Res. 103 (C10), 21683-21695.

Bathmann, U.V., Scharek, R., Klaas, C., Smetacek, V., Dubischar, C.D., 1997. Spring development of phytoplankton biomass and composition in major water masses of the Atlantic sector of the Southern Ocean. Deep-Sea Res., Part II 44, 51-68.

Bianchi, M., Feliatra, F., Tréguer, P., Vincendeau, M.A., Morvan, J., 1997. Nitrification rates, ammonium and nitrate distribution in upper layers of the water column and in the sediments of the Indian sector of the Southern Ocean. Deep-Sea Res. 44, 1017-1032.

Bronk, D.A., Glibert, P.A., Ward, B.B., 1994. Nitrogen uptake, dissolved organic nitrogen release and new production. Science $265,1843-1846$.
Bury, S.J., Owens, N.J., Preston, T., $1995 .{ }^{13} \mathrm{C}$ and ${ }^{15} \mathrm{~N}$ uptake by phytoplankton in the marginal ice zone of the Bellingshausen Sea. Deep-Sea Res. 42, 1225-1252.

Catalano, G., Benedetti, F., Goffart, A., Iorio, M., 1991. Distribution of dissolved oxygen, $\mathrm{pH}$, total alkalinity and nutrients in Southern Ocean and Ross Sea (R/V Cariboo 1989-1990 Cruise). Nat. Sc. Com. Ant., Oceanographic Campaign 198990. Data report I. pp. 11-23.

Catalano, G., Predonzani, S., Rivaro, P., Ruffini, S., 1997. Dissolved oxygen and nutrient distribution in the Ross Sea during the 1994 Austral spring (R/V Italica cruise, leg 1). In: Faranda, F.M., Guglielmo, L., Povero, P. (Eds.), Nat. Prog. Ant. Res. ROSSMIZE 93-95, Data report I. pp. 111-134.

Claustre, H., Kerhervé, P., Marty, J.C., Prieur, L., Videau, C., Hecq, J.H., 1994. Phytoplankton dynamics associated with a geostrophic front: ecological and biogeochemical implications. J. Mar. Res. 52, 711-742.

Comiso, J.C., McClain, C.R., Sullivan, C.W., Ryan, J.P., Leonard, C.L., 1993. Coastal zone color scanner pigment concentrations in the Southern Ocean and relationships to geophysical surface features. J. Geophys. Res. 98, 2419-2451.

Cota, G.F., Smith, W.O. Jr., Nelson, D.M., Muench, R.D., Gordon, L.I., 1992. Nutrient and biogenic particle distributions, primary productivity and nitrogen uptake in the WeddellScotia marginal ice zone during winter. J. Mar. Res. 50, $155-181$.

Davidson, A.T., Marchant, H.J., 1992. Protist interactions and carbon dynamics of a Phaeocystis dominated bloom at an Antarctic coastal site. Polar Biol. 12, 387-395.

DiTullio, G.R., Smith, W.O. Jr., 1995. Relationship between dimethylsulfide and phytoplankton pigment concentrations in the Ross Sea, Antarctica. Deep-Sea Res. 42, 873-892.

DiTullio, G.R., Smith, W.O. Jr., 1996. Spatial patterns in phytoplankton biomass and pigment distributions in the Ross Sea. J. Geophys. Res. 101 (C8), 18467-18477.

Dortch, Q., 1990. The interaction between ammonium and nitrate uptake in phytoplankton. Mar. Ecol. Prog. Ser. 61, 183-201.

Dugdale, R.C., Goering, J.J., 1967. Uptake of new and regenerated forms of nitrogen in primary productivity. Limnol. Oceanogr. 23, 196-206.

El-Sayed, S.Z., Biggs, D.L., Holm-Hansen, O., 1983. Phytoplankton standing crop, primary productivity and near-surface nitrogenous nutrient fields in the Ross Sea, Antarctica. Deep-Sea Res. 30, 871-886.

Eppley, R.W., Peterson, B.J., 1979. Particulate matter flux and planktonic new production in the deep ocean. Nature 282, 677-680.

Fanning, K.A., 1992. Nutrient provinces in the sea: concentration ratios, reaction rate ratios, and ideal covariation. J. Geophys. Res. 97, 5693-5712.

Gieskes, W.W.C., Kraay, G.W., 1986. Analysis of phytoplankton by HPLC before, during and after mass occurrence of the microflagellate Corymbellus aureus during the spring bloom in the open northern North Sea in 1983. Mar. Biol. 92, 45-52.

Goeyens, L., Semeneh, M., Elskens, M., Shopova, D., Baumann, M.E.M., Dehairs, F., 1998. Phytoplanktonic nutrient utilization and nutrient signature in the Southern Ocean. J. Mar. Syst. 17, 143-157. 
Goeyens, L., Sörensson, F., Tréguer, P., Morvan, J., Panouse, M., Dehairs, F., 1991. Spatiotemporal variability of inorganic nitrogen stocks and uptake fluxes in the Scotia-Weddell Confluence area during November and December. Mar. Ecol. Prog. Ser. 77, 7-19.

Goeyens, L., Tréguer, P., Baumann, M.E.M., Baeyens, W., Dehairs, F., 1995. The leading role of ammonium in the nitrogen uptake regime of Southern Ocean marginal ice zones. J. Mar. Syst. 6, 345-361.

Goffart, A., Catalano, G., Hecq, J.H., 2000. Factors controlling the distribution of diatoms and Phaeocystis in the Ross Sea. J. Mar. Syst. 27, 161-175 (this issue).

Gordon, A.L., Chen, C.T.A., Metcalf, W.G., 1984. Winter mixed layer entrainment of Weddell deep water. J. Geophys. Res. 89, 637-640.

Hansen, H.P., Grasshoff, K., 1983. Automated chemical analysis. In: Grasshoff, K., Ehrhardt, M., Kremling, K. (Eds.), Methods of Seawater Analysis. 2nd edn. Verlag Chemie, Weinheim, pp. 347-379.

Hoppema, M., Goeyens, L., Fahrbach, E., 2000. Intensive nutrient removal in the remote area off Larsen Ice Shelf (Weddell Sea). Polar Biol. 23, 85-94.

Jeffrey, S.W., 1980. Algal pigment systems. In: Falkowski, P. (Ed.), Primary Productivity in the Sea. Plenum, New York, pp. 35-58.

Jennings, J.C. Jr., Gordon, L.I., Nelson, D.M., 1984. Nutrient depletion indicates high primary productivity in the Weddell Sea. Nature 309, 51-54.

Jones, E.P., Nelson, D.M., Tréguer, P., 1990. Chemical oceanography. In: Smith, W.O. Jr. (Ed.), Polar Oceanography: Part B. Chemistry, Biology and Geology. Academic Press, San Diego, pp. 407-476.

Kamykowsky, D., Zentara, S.J., 1985. Nitrate and silicic acid in the world ocean: patterns and processes. Mar. Ecol. Prog. Ser. 26, 47-59.

Kamykowsky, D., Zentara, S.J., 1989. Circumpolar plant nutrient covariation in the Southern Ocean: patterns and processes. Mar. Ecol. Prog. Ser. 58, 101-111.

Karl, D.M., Tilbrook, B.D., Tien, G., 1991. Seasonal coupling of organic matter production and particle flux in the western Bransfield Strait, Antartica. Deep-Sea Res. 38, 1097-1126.

Koike, I., Holm-Hansen, O., Biggs, D.C., 1986. Inorganic nitrogen metabolism by antarctic phytoplankton with special Ref. to ammonium cycling. Mar. Ecol. Prog. Ser. 30, 105-116.

Kristiansen, S., Syvertsen, E.E., Farbrot, T., 1992. Nitrogen uptake in the Weddell Sea during late winter and spring. Polar. Biol. 12, 145-251.

Lancelot, C., Keller, M.D., Rousseau, V., Smith, W.O. Jr., Mathot, S., 1998. Autecology of the marine haptophyte Phaeocystis sp. In: Anderson, D.M., Cembella, A.D., Hallegraef, G.M. (Eds.), Physiological Ecology of Harmful Blooms. NATO ASI Series, vol. G 41, Springer-Verlag, Berlin, pp. 209-224.

Le Corre, P., Minas, M.J., 1983. Distributions et évolution des élements nutritifs dans le secteur Indien de l'Océan Antarctique en fin de période estivale. Oceanol. Acta 6, 365-381.

Leventer, A., Dunbar, R.B., 1996. Factors influencing the distribution of diatoms and other algae in the Ross Sea. J. Geophys. Res. 101 (C8), 18489-18500.
Lipizer, M., Catalano, G., 1999. Nitrogen assimilation and new production in a Spring Bloom in the Ross Sea. (Cruise of R/V Italica, 1994). In: Faranda, F.M., Guglielmo, L., Povero, P. (Eds.), Nat. Prog. Ant. Res. ROSSMIZE 93-95, Data report II.

Mathot, S., Dandois, J.M., Lancelot, C., 1992. Gross and net primary production in the Scotia-Weddell Sea sector of the Southern Ocean during spring 1988. Polar Biol. 12, 321-332.

Nelson, D.A., Smith, W.O. Jr., 1986. Phytoplankton bloom dynamics of the western Ross ice edge: II. Mesoscale cycling of nitrogen and silicon. Deep-Sea Res. 33, 1389-1412.

Nelson, D.M., Smith, W.O. Jr., Gordon, L.I., Huber, B.A., 1987. Spring distributions of density, nutrients, and phytoplankton biomass in the ice edge zone of the Weddell-Scotia Sea. J. Geophys. Res. 92, 7181-7190.

Olson, R.J., 1980. Nitrate and ammonium uptake in Antarctic waters. Limnol. Oceanogr. 25, 1064-1074.

Owens, N.J.P., 1988. Rapid and total automation of shipboard ${ }^{15} \mathrm{~N}$ analysis: examples from the North Sea. J. Exp. Mar. Biol. Ecol. 122, 163-171.

Owens, N.J.P., Priddle, J., Whitehouse, M.J., 1991. Variations in phytoplanktonic nitrogen assimilation around South Georgia and in Bransfield Strait (Southern Ocean). Mar. Chem. 35, 287-304.

Owens, N.J.P., Rees, A.P., 1989. Determination of ${ }^{15} \mathrm{~N}$ at sub-microgram levels of nitrogen using automated continuous-flow Isotope Ratio Mass Spectrometry. Analyst 114, 1657-1665.

Palmisano, A.C., Soohoo, J.B., SooHoo, S.L., Kottmeier, S.T., Craft, L.L., Sullivan, C.W., 1986. Photoadaptation in Phaeocystis pouchetii advected beneath the sea ice in McMurdo Sound, Antartica. J. Plankton Res. 8, 891-906.

Quéguiner, B., Tréguer, P., Peeken, I., Scharek, R., 1997. Biogeochemical dynamics and the silicon cycle in the Atlantic sector of the Southern Ocean during austral spring 1992. Deep-Sea Res. II 44, 69-90.

Rubin, S.I., Takahashi, T., Chipman, D.W., Goddard, J.G., 1998. Primary productivity and nutrient utilization ratios in the Pacific sector of the Southern Ocean based on seasonal changes in seawater chemistry. Deep-Sea Res. I 45, 1211-1234.

Sakshaug, E., Holm-Hansen, O., 1984. Factors governing pelagic production in polar oceans. In: Holm-Hansen, O., Bolin, B., Gilles, R. (Eds.), Marine Phytoplankton and Productivity. Springer-Verlag, Berlin, pp. 1-18.

Semeneh, M., Dehairs, F., Elskens, M., Baumann, M.E.M., Kopczynska, E.E., Lancelot, C., Goeyens, L., 1998a. Nitrogen uptake regime and phytoplankton community structure in the Atlantic and Indian sectors of the Southern Ocean. J. Mar. Syst. 17, 159-177.

Semeneh, M., Dehairs, F., Fiala, M., Elskens, M., Goeyens, L., 1998 b. Seasonal variation of phytoplankton community structure and nitrogen uptake regime in the Indian sector of the Southern Ocean. Polar Biol. 20, 259-272.

Smith, W.O. Jr., Sakshaug, E., 1990. Polar phytoplankton. In: Smith, W.O. Jr. (Ed.), Polar Oceanography: Part B. Chemistry, Biology and Geology. Academic Press, San Diego, pp. 477-525.

Smith, W.O. Jr., Nelson, D.M., DiTullio, G.R., Leventer, A.R., 1996. Temporal and spatial patterns in the Ross Sea: phyto- 
plankton biomass, elemental composition, productivity and growth rates. J. Geophys. Res. 101 (C8), 18455-18465.

Sullivan, C.W., McClain, C.R., Comiso, J.C., Smith, W.O. Jr., 1988. Phytoplankton standing crops within an Antarctic ice edge assessed by satellite remote sensing. J. Geophys. Res. 93, 12487-12498.

Tréguer, P., Jacques, G., 1992. Dynamics of nutrients and phytoplankton, and fluxes of carbon, nitrogen and silicon in the Antarctic Ocean. Polar Biol. 12, 149-162.

Tréguer, P., Le Corre, P., 1975. Manuel d'analyse des sels nutritifs dans l'eau de mer. Université de Bretagne Occidentale, Brest, France, $110 \mathrm{pp}$.

Wilkerson, F.P., Dugdale, R.C., 1992. Measurements of nitrogen productivity in the Equatorial Pacific. J. Geophys. Res. 97 (C1), 669-679.

Williams, R., Claustre, H., 1991. Photosynthetic pigments as biomarkers of phytoplankton populations and processes involved in the transformation of particulate organic matter at the Biotrans site $\left(47^{\circ} \mathrm{N}, 20^{\circ} \mathrm{W}\right)$. Deep-Sea Res. 38, 347-355. 